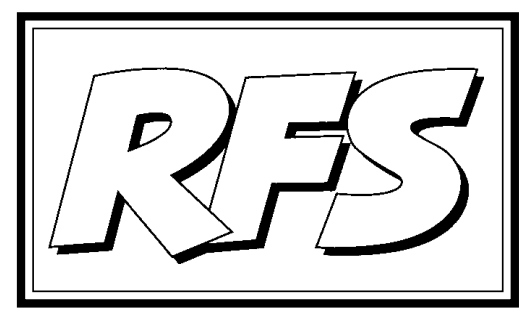

Revista de Fomento Social, 56 (2001), 65-91

\title{
La Comunidad Andina: 30 años en busca del desarrollo
}

\section{Angel María CASAS GRAGEA ${ }^{1}$}

\begin{abstract}
"Las posibilidades naturales de este hemisferio son cuantiosas; el hombre americano, síntesis de síntesis, con su amplitud y su espíritu libre, sin el lastre de torvos fanatismos, puede ser el exponente de un tiempo ciertamente nuevo para la humanidad"
\end{abstract}

José Luis Salcedo²

\section{Introducción}

Los países que forman el área andina tienen muchas semejanzas. Los cinco tienen el español como idioma oficial y algunos comparten lenguas precolombinas. Su sistema de gobierno está basado en una democracia presidencial ista

1 Licenciado en CC. Económicas y Empresariales. Doctorando de la Facultad de CC. Económicas y Empresariales (ETEA). Universidad de Córdoba. Actualmente amplía estudios sobre integración en la Universidad de Lima. Artículo revisado en octubre de 2000. El autor agradece al profesor Pedro Caldentey del Pozo sus observaciones a una versión preliminar del presente texto.

2 Salcedo Bastardo, J osé Luis, Bolívar: un continente y un destino. Caracas 1972, p. 385. 
y a lo largo de los años han aplicado estrategias económicas aparentemente similares. Se encuentran unidos por una de las cadenas montañosas más importantes del planeta y los cinco consiguieron la independencia de la Corona española de manos del Libertador Simón Bolívar que ya entonces soñó un área políticamente integrada que recibiría el nombre de la Gran Colombia.

El 26 de mayo de 1999, en la ciudad colombiana de Cartagena de Indias, se celebró el trigésimo aniversario del Acuerdo de Cartagena que había dado lugar al nacimiento de uno de los esquemas de integración más antiguos y menos conocidos del universo integracionista. Este día se conmemoraba no sólo un pasado cargado de luces y sombras, de indiferencia y descreimiento, de sueño conjunto y empuje, sino que se celebraba con optimismo la esperanza ante un destino en común.

La Comunidad Andina de Naciones (CAN) es una organización subregional deAmérica del Sur integrada por los estados soberanos de Bolivia, Colombia, Ecuador, Perú y Venezuela. J untos reúnen 111 millones de habitantes a lo largo de $4.718 .322 \mathrm{~km}^{2}$ de superficie, lo que representa el $16 \%$ y el $26 \%$ respectivamente del total de América del Sur.

Pese a estas aparentes similitudes geográficas, políticas, económicas y humanas, cada uno de los países and inos presenta una gran diversidad dentro de sus fronteras. La contemplación de la región como un conjunto pone de manifiesto la riqueza y complejidad que siempre aporta la diversidad.

En el ámbito económico, los países andinos no se han desarrollado de forma pareja ni han alcanzado resultados económicos similares a lo largo de las últimas décadas. Aunque las intenciones de crecer como área integrada económicamente se vienen explicitando desde la firma del Acuerdo de Cartagena (1969), en la práctica la evolución ha sido heterogénea y con comportamientos distintos en cada país según los períodos. Valga como ejemplo el intento de desarrollar la industria a partir del modelo de sustitución de importaciones, que propuso la CEPAL en los años 60, y que no se hizo utilizando los mismos instrumentos económicos en cada país. Más tarde, el predominio del modelo neoliberal se manifestó en formas y etapas distintas en cada país.

Los países de la CAN se encuentran en la zona intermedia del desarrollo humano (Perú, Ecuador, Bolivia), o en la parte baja de la zona de alto desarrollo humano (Venezuela y Colombia). Presentan una gran desigualdad en la distribución de la renta, con la mayoría de su población viviendo en el umbral de la pobreza y con altos niveles de endeudamiento externo.

\section{RFS}




\section{Un recorrido por los rasgos generales de los países miembros de la Comunidad Andina}

\section{Rasgos generales de los países andinos 1999}

\begin{tabular}{|l|c|c|c|}
\hline & $\begin{array}{c}\text { Población } \\
\text { (Millones de } \\
\text { habitantes) }\end{array}$ & $\begin{array}{c}\text { Superficie } \\
\text { (Miles de km2) }\end{array}$ & $\begin{array}{c}\text { PIB } \\
\text { (Millones de } \\
\text { US\$ corrientes) }\end{array}$ \\
\hline Bolivia & 8,1 & 1.099 & 8.617 \\
\hline Colombia & 41,6 & 1.139 & 90.102 \\
\hline Ecuador & 12,4 & 284 & 13.769 \\
\hline Perú & 25,2 & 1.285 & 57.118 \\
\hline Venezuela & 23,7 & 912 & 102.225 \\
\hline Comunidad Andina & 111,1 & 4.719 & 271.831 \\
\hline Sudamérica & 339,8 & 17.295 & 1.205 .159 \\
\hline
\end{tabular}

Fuente: Elaborado a partir de los datos de la Comunidad Andina y El estado del mundo (1999).

El cuadro muestra la importancia relativa de la Comunidad Andina con respecto al conjunto Latinoamericano en términos de superficie, población y PIB. Muestra también los datos básicos de los países que la forman y la magnitud de los datos de superficie y población de esta gran subregión latinoamericana en comparación con las cifras sudamericanas. Presentamos a continuación algunos detalles específicos de cada uno de los miembros de la CAN. En este breve perfil, destacaremos la existencia de marcos políticos notablemente convulsos en varios de los países de la región, que dificultan la integración económica y política de la subregión.

\subsection{Bolivia}

Este país andino es el más meridional de la Comunidad Andina y corazón del subhemisferio americano. Es junto a Perú el país más grande pero presenta una baja densidad de población debido a las grandes zonas desha- 
bitadas de la selva preamazónica y algunas zonas del Altiplano.

El 6 de agosto de 1997 tomó posesión como presidente de la República Hugo Banzer, el ex dictador ${ }^{3}$ de 72 años con sólo el $20,8 \%$ de los votos. El viejo ex dictador ha seguido la línea reformista del gobierno anterior aunque de forma mucho más conservadora y con varios escándalos de corrupción a sus espaldas.

Bolivia es uno de los países más pobres de la subregión andina y de toda Sudamérica. Su PIB, total y per cápita, es el más bajo del área y mantiene una balanza de pagos deficitaria de 452 millones de dólares. Pese a estas debilidades, mostró hasta 1998 los mejores ritmos de crecimiento del PIB ( $4,7 \%$ en 1998), tendencia que ha cambiado bruscamente en 1999 con una tasa de crecimiento de sólo el 0,8\%, y la menor tasa de inflación de la subregión. La evolución de estos indicadores le han otorgado la fama de ser uno de los países más aplicados con las directrices marcadas por los organismos internacionales y como consecuencia ha visto incrementado su nivel de inversión extranjera directa en más de 6 puntos, pasando a ser, en términos relativos, el país con mejores cifras relativas de inversión extranjera.

El gobierno se ha comprometido a erradicar totalmente las plantaciones de hoja de coca, de la que Bolivia es uno de los mayores productores mundiales, antes del año 2002 y para ello, va a recibir una ayuda internacional de 809 millones de dólares en este perío do. Por otro lado, Bolivia se comprometió en 1998 con el Club de París ${ }^{4}$ a mantener un nivel de crecimiento del $4,3 \%$ del PIB - que no ha cumplido en 1999 - y seguir disminuyendo sus niveles de pobreza. A cambio ha recibido un crédito por la cantidad de 942 millones de dólares y la posibilidad de reducir en 100 millones de dólares los costes financieros de su deuda externa, lo queha disminuido los más de 400 millones anuales que paga por el servicio de su deuda, una cifra equivalente a su gasto público en educación en 1995.

A pesar del aparente éxito de los Programas de Ajuste Estructural (PAE) y del Programa de Liberalización comercial en este país, la tasa de crecimiento, que durante la segunda mitad de la década se había mantenido en un nivel superior al 4\%, no ha superado el $1 \%$ en 1999; y, además, no hay que olvidar

3 Entre 1971 y 1978 ejerció la dictadura en su país.

4 Como es sabido, desde 1976, es una agrupación internacional de los acreedores públicos y delos representantes del FMI y del Banco Mundial en el seno del cual se discuten los acuerdos de renegociación y reprogramación de la deuda exterior de los países del Tercer Mundo.

\section{RFS}


las movilizaciones que desde el mes de abril de 2000 han sacado a las calles el descontento de la población y donde, incluso, se ha pedido la destitución del presidente Banzer.

\section{Cuadro no 2 \\ Bolivia: principales indicadores}

\begin{tabular}{|l|r|r|r|r|}
\hline INDICADOR & 1994 & 1996 & 1998 & 1999 \\
\hline PIB total (millones de \$) & 6.487 & 7.397 & 8.575 & 8.617 \\
\hline PIB per cápita (\$) & 897 & 974 & 1.078 & 1.058 \\
\hline PIB real total (\%) (1) & 4,7 & 4,4 & 4,7 & 0,8 \\
\hline $\begin{array}{l}\text { Exportaciones FOB al mundo } \\
\text { (millones de \$) }\end{array}$ & 1.041 & 1.078 & 1.325 & 1.402 \\
\hline Balanza comercial (millones de \$) & -155 & -565 & -1057 & -452 \\
\hline Inflación (\%) (2) & 8,5 & 7,9 & 4,4 & 3,1 \\
\hline $\begin{array}{l}\text { Inversión extranjera directa } \\
\text { anual por \% del PIB }\end{array}$ & 2,1 & 6,6 & 8,6 & \\
\hline
\end{tabular}

Fuente: elaborado a partir de los datos de la Comunidad Andina

(1) tasa de crecimiento anual de los valores constantes

(2) variación porcentual acumulada enero-diciembre

\subsection{Colombia}

Este país, marcado por la violencia de la guerrilla y el narcotráfico, es uno de los más grandes y ricos de la Comunidad. Desde agosto de 1998, está siendo gobernado por Andrés Pastrana, del partido conservador, tras 4 años de polémico gobierno del ex presidente Samper del Partido Liberal.

En 1997, el conflicto armado provocó 6.000 víctimas mortales y murieron, en todo el país, por causas violentas 31.806 personas. Durante el periodo preelectoral, las Fuerzas Armadas Revolucionarias de Colombia (FARC), de 12.000 hombres aproximadamente, manifestaron su preferencia por Andrés Pastrana, hecho que facilitó el inicio de un proceso de diálogo entre el gobierno y las fuerzas revolucionarias para buscar la paz en el país, que se ha visto frustrado con posterioridad. Este proceso ha desembocado en la 
controvertida propuesta del "Plan Colombia"5 por parte del actual gobierno, que busca el desarrollo de una estrategia integrada para enfrentar los desafíos más apremiantes que se le plantean actualmente al país, especialmente el narcotráfico y la guerrilla. La propuesta de Pastrana ha encontrado apoyo en los Estados Unidos y algunos países de Europa, aunque ha despertado una gran preocupación en la población colombiana y en la de los países fronterizos.

En mayo de 1999 en Cartagena (Colombia), durante la celebración de la Cumbre Presidencial, el Consejo Andino de Cancilleres aprobó la Decisión 458 en la que se establecen los objetivos, los fundamentos y el contenido programático de la Política Externa Común andina. Sin embargo, y a pesar de la aprobación de estos instrumentos de política externa subregional y de afectar directamente a países fronterizos como Ecuador, la propuesta del "Plan Colombia", por parte del gobierno colombiano, ha sido unilateral frente a Estados Unidos y a Europa.

Sin duda la situación política del país está teniendo consecuencias muy graves para su economía. El PIB en 1999 decreció un -4,8\%, La inversión extranjera se ha reducido entre 1994 y 1998 de 2,4 \% al 1,5\% del PIB. Estos bajos índices y la pérdida de confianza de los inversores locales han hecho que el desempleo alcance el nivel histórico del $18 \%$ de la población activa en el año 1999. Todo esto se ha visto acompañado por una constante devaluación de su moneda frente al dólar y un agravamiento de la carga de la deuda externa con unos costes financieros anuales, pagados en dólares americanos, del $37 \%$ de las exportaciones.

5 En octubre de 1999, de manera secreta, el presidente de la República de Colombia, Andrés Pastrana, y el embajador de la República de Colombia en Washington, Luis Alberto Moreno, entregaron al Gobierno de los Estados Unidos el «Plan Colombia» Como argumentación para solicitar la «ayuda militar»adicional de US\$1.500 millones. El Plan fue aprobado por el Senado de Estados Unidos el 23 de junio de 2000. 
Cuadro no 3

Colombia: principales indicadores

\begin{tabular}{|l|r|r|r|r|}
\hline INDICADOR & 1994 & 1996 & 1998 & 1999 \\
\hline PIB total (millones de \$) & 81.708 & 97.148 & 99.356 & 90.102 \\
\hline PIB per cápita (\$) & 2.162 & 2.473 & 2.435 & 2.168 \\
\hline PIB real total (\%) (1) & 5,8 & 2,1 & 0,6 & $-4,8$ \\
\hline $\begin{array}{l}\text { Exportaciones FOB al mundo } \\
\text { (millones de \$) }\end{array}$ & 8.408 & 10.562 & 10.790 & 11.549 \\
\hline Balanza comercial (millones de \$) & -3.448 & -3.793 & -3.888 & 890 \\
\hline Inflación (\%) (2) & 22,6 & 21,6 & 16,7 & 9,3 \\
\hline $\begin{array}{l}\text { Inversión extranjera directa } \\
\text { anual por \% del PIB }\end{array}$ & 2,4 & 3,8 & 1,5 & \\
\hline
\end{tabular}

Fuente: elaborado a partir de los datos de la Comunidad Andina

(3) tasa de crecimiento anual de los valores constantes

(4) variación porcentual acumulada enero-diciembre

\subsection{Ecuador}

Es el país más pequeño en superficie de la subregión, aunque cuenta con mayor número de habitantes que Bolivia cuya superficie es cinco veces mayor. Tiene unos de los niveles de PIB más bajos de la Comunidad y dos tercios de su población se encuentran en el umbral de la pobreza.

Ecuador ha vivido un reciente período de convulsión política. El exalcalde de Quito, J amil Mahuad, ejerció la jefatura de gobierno desde agosto de 1998 tras acceder al poder en medio de una crisis política que habían provocado el populista Abdalá Bucaram, destituido de la presidencia y exiliado en febrero de 1997, y su sucesor Fabián Alarcón, hasta hace poco en prisión. Mahuad fue relevado en la presidencia ${ }^{6}$ del país tras la protesta social liderada por las organizaciones indígenas y apoyada por diversos sectores sociales del país. La raíz del conflicto es la profunda crisis económica y política cuyas consecuencias se están mostrando trágicas para la población

6 El gobierno ecuatoriano está presidido desde enero de 2000 por el demócrata cristiano Gustavo Noboa. 
y que se ha visto agravada por el fenómeno climático El Niño. Este fenómeno provocó importantes desastres naturales con 20.000 víctimas, varios centenares de muertos y daños materiales evaluados en 3.000 millones de dólares en 1997-1998.

Como consecuencia de los gastos en la reconstrucción de infraestructuras, la caída del precio del petróleo en 1998, principal fuente de ingresos estatales, y una política de gasto sin moderación, el déficit fiscal aumentó su porcentaje sobre el PIB del 2,6 \% en 1997 al 5,7 \% en 1998. El Estado se vio obligado a la venta anticipada de petróleo y a recurrir a los créditos internacionales.

El conjunto de medidas que despertó la reacción social tenía como objetivo principal el control del acelerado desplome de la moneda local respecto al dólar (del 141,2\% de mayo de 1999 hasta mayo de 2000) ${ }^{7}$ y del elevado nivel de inflación (60,7\% en 1999). En enero de 2000, el Gobierno tomó la decisión de dolarizar ${ }^{8}$ la economía. Esta medida había sido precedida por el inaudito congelamiento, en 1999, por un año, del $50 \%$ de las cuentas corrientes y de ahorro y el $100 \%$ de los depósitos a plazo en dólares y en moneda local. Todo esto está creando una situación de iliquidez, suavizada temporal mente por la subida en los precios del petróleo, que prácticamente ha paralizado la producción y ha provocado una fuerte caída de la demanda interna. Además, la inflación ecuatoriana desde junio de 1999 hasta junio de 2000 fue de 103,7\%, lo que está suponiendo un mayor empobrecimiento de la población. El Fondo Monetario Internacional (FMI) ha concedido un crédito por un valor de 900 millones de dólares con la condición de que el Gobierno tome medidas drásticas e impopulares que supondrán un aumento en los impuestos y un severo recorte de los subsidios. No hay que olvidar que Ecuador, en términos relativos, es el país más endeudado con el exterior de la Comunidad. En 1998 su deuda externa era el $82 \%$ del PIB y se pagaron 1.200 millones de dólares en intereses, superior a la cantidad que han recibido del FMI.

La crisis ecuatoriana añade nuevos elementos desestabilizadores a los compromisos adoptados hasta la fecha por los cinco países andinos. El proyecto de moneda única andina, si ya era difícil, ahora se ha vuelto casi

7 A partir de febrero de 2000, la devaluación ha sido cero debido al establecimiento de un tipo de cambio fijo de 25.000 sucres por dólar.

8 El 7 de enero de 2000, el Ecuador adoptó un nuevo modelo monetario denominado dolarización. Éste consiste en la utilización de la moneda norteamericana como medio de pago en cualquier tipo de transacción. El 9 de septiembre la moneda ecuatoriana, el sucre, fue definitivamente sustituida por el dólar norteamericano. 
imposible tras la dolarización ecuatoriana. Otro elemento preocupante es el nuevo proyecto de descentralización del Estado. Ambas medidas se han planteado de espaldas a la subregión andina y podrían terminar excluyendo a Ecuador de la Comunidad Andina de Naciones.

Cuadro no 4

Ecuador: principales indicadores

\begin{tabular}{|l|r|r|r|r|}
\hline INDICADOR & 1994 & 1996 & 1998 & 1999 \\
\hline PIB total (millones de \$) & 16.880 & 19.157 & 19.739 & 13.769 \\
\hline PIB per cápita (\$) & 1.504 & 1.638 & 1.612 & 1.109 \\
\hline PIB real total (\%) (1) & 4,3 & 2 & 0,4 & $-7,3$ \\
\hline $\begin{array}{l}\text { Exportaciones FOB al mundo } \\
\text { (millones de \$) }\end{array}$ & 3.725 & 4.900 & 4.141 & 4.207 \\
\hline Balanza comercial (millones de \$) & 75 & 968 & -1.362 & 1.392 \\
\hline Inflación (\%) (2) & 25,3 & 25,5 & 43,4 & 60,7 \\
\hline $\begin{array}{l}\text { Inversión extranjera directa } \\
\text { anual por \% del PIB }\end{array}$ & 3,1 & 2,5 & 3,2 & \\
\hline
\end{tabular}

Fuente: elaborado a partir de los datos de la Comunidad Andina

(5) tasa de crecimiento anual de los valores constantes

(6) variación porcentual acumulada enero-diciembre

\subsection{Perú}

Es el país de mayor superficie del área andina con una situación geográfica que lo convierte en la bisagra que articula el territorio de la subregión. Esta situación geoestratégica favorable permitió que, en su momento, Lima fuese la sede de la J unta del Acuerdo de Cartagena y, que, actualmente sea la de la Secretaría General de la Comunidad Andina.

El presidente de la República fue, desde 1990, el controvertido Alberto Fujimori. El mandatario peruano, presidente electo democráticamente en dos ocasiones, no secaracterizó por su defensa de la democracia y delos derechos humanos que se vieron violados frecuentemente durante su mandato. Son conocidos también los recientes episodios electorales que llevaron primero 
a Fujimori a su tercer período presidencial tras unas elecciones manipuladas y a su caída y huida posterior. Estos acontecimientos han restado credibilidad democrática al régimen y han mostrado la imposibilidad de la CAN de influir en los procesos democráticos internos de sus países miembros ${ }^{9}$.

Perú, al igual que Ecuador, ha sufrido el fenómeno climático El Niño, que a su paso ha dejado unas 300.000 personas afectadas y unas pérdidas que se valoran en 2.000 millones de dólares.

En los últimos años la economía peruana consiguió elevadas tasas de crecimiento de su PIB: 13,1 \% en 1994 y 7,2 \% en 1997. Sin embargo, esta tendencia parece haber cambiado con nivel de crecimiento del 0,3\% en 1998 y del 3,8\% en 1999; además, la tasa de desempleo se mantiene, aproximadamente, en el $8 \%$ de la población activa. La deuda externa total del país en 1998 era de 32.000 millones de dólares y su servicio anual sobrepasó los 2.000 millones de dólares. La misma cantidad de dinero en que se evaluaron las pérdidas ocasionadas por El Niño y el doble del gasto público anual en sanidad.

\section{Cuadro no 5 \\ Perú: principales indicadores}

\begin{tabular}{|l|r|r|r|r|}
\hline INDICADOR & 1994 & 1996 & 1998 & 1999 \\
\hline PIB total (millones de \$) & 50.247 & 60.921 & 62.810 & 57.118 \\
\hline PIB per cápita (\$) & 2.174 & 2.544 & 2.533 & 2.264 \\
\hline PIB real total (\%) (1) & 13,1 & 2,4 & 0,3 & 3,8 \\
\hline $\begin{array}{l}\text { Exportaciones FOB al mundo } \\
\text { (millones de \$) }\end{array}$ & 4.361 & 5.835 & 5.640 & 5.973 \\
\hline Balanza comercial (millones de \$) & -1.268 & -1.940 & -2.458 & -558 \\
\hline Inflación (\%) (2) & 15,4 & 11,8 & 6,0 & 3,7 \\
\hline $\begin{array}{l}\text { Inversión extranjera directa } \\
\text { anual por \% del PIB }\end{array}$ & 6,1 & 5,3 & 3,3 & \\
\hline
\end{tabular}

Fuente: elaborado a partir de los datos de la Comunidad Andina

(1) tasa de crecimiento anual de los valores constantes

(2) variación porcentual acumulada enero-diciembre

9 Ya en prensa el presente texto, se producen las elecciones con resultados aún no definitivos (Nota de la redacción).

\section{RFS}




\subsection{Venezuela}

Es el país más septentrional de la subregión andina y el más rico gracias a sus grandes reservas de petróleo. En el Índice de Desarrollo Humano que elabora cada año el Programa de la Naciones Unidas para el Desarrollo (PNUD, 1997) aparece en la posición 47 entre los países de alto desarrollo humano, por encima de Colombia que ocupa el puesto 51.

Tampoco Venezuela se libra de la inestabilidad política. El ex coronel golpista Hugo Chávez ${ }^{10}$ es su presidente desde diciembre de 1998. Chávez es un político populista y con ademanes dictatoriales que llegó al poder gracias al apoyo popular tras autoerigirse como futuro heraldo contra la corrupción y las desigualdades sociales existentes en su país. Ha puesto en marcha una Asamblea constituyente que ha aprobado una profunda reforma del Estado con criterios alejados de las democracias representativas. Recientemente se retrasó la fecha de celebración de las primeras elecciones post-constituyentes. La enorme po pularidad de Chávez, que lo llevó a la presidencia mediante la virtual desaparición de toda oposición y los partidos tradicionales del país, parece decrecer en los últimos meses.

En 1996, los colaboradores del anterior presidente, Rafael Caldera, y los asesores del FMI firmaron la Agenda Venezuela, la puesta de largo del neoliberalismo en Venezuela, que se ha visto frustrada tras la subida al poder de Chávez. Las previsiones que se hicieron al firmar la Agenda se revelan ahora optimistas, puesto que aunque la inflación ha disminuido se sigue manteniendo en un nivel cercano al $20 \%$, la tasa de desempleo ha aumentado hasta alcanzar el $14,5 \%$ de la población activa y el crecimiento del PIB mantiene tasas negativas. El descenso en los precios del petróleo en 1998 afectó gravemente a las exportaciones y a las cuentas públicas, que pasaron de un superávit del 2,3\% del PIB en 1997 a un déficit del 5,5\% del PIB en 1998, lo que deja a la luz la gran dependencia que tiene la economía venezolana respecto a este recurso no renovable.

Tras la somera descripción anterior de cada uno de los miembros de la Comunidad Andina, podemos observar que se trata de países que están atravesando por graves problemas políticos y económicos que convierten a la subregión andina en un "polvorín" que podría estallar en cualquier momento. Además, las economías andinas persisten en sus problemas estructurales, lo que las hace tremendamente vulnerables a los embates externos.

10 Lideró el intento de golpe de estado de 1992 contra el socialdemócrata Carlos Andrés Pérez. 
A partir de ahora, analizaremos el proceso de integración andino desde una perspectiva histórica. El regionalismo andino es un fenómeno con más de treinta años de vida, que nació, como ya hemos mencionado, con el objetivo de promover el desarrollo equilibrado y armónico de los países miembros aprovechando las ventajas de un espacio económico y político ampliado. La perspectiva histórica nos va a mostrar los distintos compromisos y modelos regionales queha adoptado la subregión, desdeel pobremente entendido modelo de sustitución de importaciones hasta el tibio eind efinido regionalismo abierto; las distintas miradas de la integración regional como estrategia de desarrollo; y la influencia de la integración en la conformación de la anatomía actual, económica y política, de los cinco países andinos.

\section{Cuadro no 6}

Venezuela: principales indicadores

\begin{tabular}{|l|r|r|r|r|}
\hline INDICADOR & 1994 & 1996 & 1998 & 1999 \\
\hline PIB total (millones de \$) & 58.244 & 70.536 & 95.206 & 102.225 \\
\hline PIB per cápita (\$) & 2.724 & 3.161 & 4.096 & 4.312 \\
\hline PIB real total (\%) (1) & $-2,3$ & $-0,2$ & $-0,1$ & $-7,2$ \\
\hline $\begin{array}{l}\text { Exportaciones FOB al mundo } \\
\text { (millones de \$) }\end{array}$ & 16.717 & 23.125 & 17.001 & 20.080 \\
\hline Balanza comercial (millones de \$) & 8.316 & 13.804 & 1.953 & 7.442 \\
\hline Inflación (\%) (2) & 70,6 & 104,5 & 28,3 & 18,8 \\
\hline $\begin{array}{l}\text { Inversión extranjera directa } \\
\text { anual por \% del PIB }\end{array}$ & 1 & 2,4 & 4,5 & \\
\hline
\end{tabular}

Fuente: elaborado a partir de los datos de la Comunidad Andina.

(1) Tasa de crecimiento anual de los valores constantes.

(2) Variación porcentual acumulada enero-diciembre. 


\section{La historia de la integración andina}

\subsection{El Acuerdo de Cartagena de 1969}

El día 26 de mayo de 1969, los gobiernos de Chile, Colombia, Bolivia, Ecuador y Perú firmaron el Acuerdo de Cartagena. En 1973, Venezuela lo asumió y se incorporó a éste. En 1976, Chile abandonó el Grupo, principalmente, por estar en desacuerdo con los niveles arancelarios establecidos en el Arancel Externo Común ${ }^{11}$ (AEC). El Acuerdo de integración subregional andino, bautizado con el nombre de Pacto Andino, tenía por objetivo (Art. 1) promover el desarrollo equilibrado y armónico de los países miembros, acelerar su crecimiento mediante la integración económica, facilitar su participación en el proceso de integración latinoamericano previsto en el Tratado de Montevideo (1960) fundador de la Asociación Latinoamericana de Libre Comercio (ALALC) y establecer condiciones favorables para la constitución de un mercado común latinoamericano.

El Pacto Andino se creó aprovechando los últimos impulsos del auge integracionista que experimentó América Latina en las décadas de los cincuenta y sesenta. La reflexión sobre la función de los mecanismos de integración regional en el modelo de sustitución de importaciones diseñado por la CEPAL para la región, constituyó un importante estímulo para su creación. La participación de los países andinos en la ALALC condicionó también la puesta en marcha y diseño de los objetivos del Pacto. El Tratado de Montevideo fue suscrito por Argentina, Bolivia, Brasil, Colombia, Chile, Ecuador, México, Paraguay, Perú, Uruguay y Venezuela.

La ALALC tenía como principal objetivo la creación de un mercado común latinoamericano, aunque no se establecieron ni plazos ni mecanismos. Las dificultades para alcanzar este objetivo hicieron languidecer su fuerza inicial e impedir su éxito como proyecto de integración hemisférica. Según Walter Mattli12 esto se debió a la ausencia de dos condiciones importantes para que un proceso de integración tenga éxito. En primer lugar, una demanda

11 Como es sabido, es la tarifa o gravamen uniforme que los países que participan en un esquema de integración aplican a las importaciones procedentes de terceros países. Su adopción define la fase de Unión aduanera en un proceso de integración económica, superior a la Zona de Libre Comercio y previa a la formación del Mercado Común.

12 Mattli, W. (1999), p. 146 
sostenible de la integración y, en segundo, la existencia de un liderazgo regional. Ante la falta de un hegemón benigno, como otros autores Ilaman al líder regional, no se produjo una redistribución de los beneficios de la integración entre to dos los países miembros y estos, aunque modestamente, se concentraron en los tres "gigantes" regionales (Brasil, Argentina y México). En respuestas a estos fallos internos de la ALALC, los países andinos se plantearon su integración económica para conseguir conjuntamente un desarrollo industrial adecuado, una aceleración en el crecimiento, un incremento de los niveles de vida; y así nivelarse a los estados de mayor desarrollo y posteriormente poder incorporarse al mercado común latinoamericano. Sin embargo, la crisis de los años ochenta frenó bruscamente el desarrollo de los acuerdos de integración.

La ALALC se transformó en 1980 en la Asociación Latinoamericana de Integración (ALADI), cuya base jurídica es el Tratado de Montevideo de 1980. La ALADI nació como un acuerdo de liberalización comercial más flexible y situó su interés prioritario en los acuerdos bilaterales o plurilatelares en apoyo a la multilateralización necesaria para alcanzar el mercado común latinoamericano.

\subsection{La crisis de los años 80 y la década perdida}

Se denomina así a la grave crisis estructural que afectó a los países latinoamericanos en la década de los 80 . En el ámbito económico se produjo una caída en la competitividad y en la productividad de los países andinos. Políticamente fue una época marcada por el ascenso al poder de gobiernos dictatoriales en toda la subregión.

Los conocidos detonantes externos que hicieron estallar la crisis fueron: el deterioro en los intercambios comerciales después de 1981, la crisis en los países industrializados después de la segunda crisis del petróleo, la tendencia del mundo desarrollado a proteger sus mercados, la caída en los niveles de inversión extranjera y el drástico corte en los flujos internacionales de capital, la elevación de los tipos de interés internacionales y el constante incremento de la deuda externa que en 1982 produjo el estallido de la llamada crisis de la deuda tras el anuncio de México, y del resto de otros países latinoamericanos en cadena, de una moratoria en sus pagos internacionales.

Por otra parte hubo una serie de factores de carácter intrínseco que no ayudaron a la integración en estos momentos de crisis: el Acuerdo de

\section{RFS}


Cartagena había tenido un carácter exageradamente industrialista que dejó de lado al sector agropecuario y social, y el arancel externo común se estableció a unos niveles muy altos y dispersos que trajeron como consecuencia difíciles negociaciones que no consiguieron su aceptación final.

Durante el período de crisis, los países andinos terminaron aplicando entre sí medidas proteccionistas contradictorias con los acuerdos regionales. Estas medidas, la caída del comercio en la subregión y la no resolución de los conflictos anteriores pusieron en cuestión la propia existencia del proceso de integración.

\subsection{Etapa de reactivación del proceso de integración}

a) Protocolo de Quito de 1987

Tras las tormentas que sacudieron a los países latinoamericanos durante los ochenta, los países del Grupo Andino se volvieron a reunir en Quito el 12 de mayo de 1987 para revisar el Acuerdo de Cartagena. Su intención era devolver el aliento al proceso de integración mediante la modernización de la estructura productiva subregional, la búsqueda de una mayor competitividad y un mayor poder de negociación en la esfera internacional.

En el Protocolo de Quito se revisó el calendario establecido en el Acuerdo de Cartagena, del que no se había cumplido ni la Programación Industrial, ni el Programa de Liberalización ni la adopción del AEC. También se contemplaron medidas para estimular el desarrollo agropecuario, desatendido en la etapa anterior.

Después de la crisis de los años 80 , el pensamiento económico neoliberal se introdujo con fuerza en algunos de los países latinoamericanos, como por ejemplo en el caso chileno, con gran influencia en toda Latinoamérica. Los países andinos también fueron objeto de esta influencia que condujo a un planteamiento más flexible del marco legal del Acuerdo de Cartagena y una mayor apertura hacia la economía de mercado.

Las medidas adoptadas, que modificaron el modelo inicial, fueron: una mayor apertura a la competencia externa, eliminación de restricciones administrativas a la importación, eliminación de las restricciones a la inversión extranjera, reforma de los modelos de administraciones públicas del Estado, la privatización de parte de las actividades del Estado, una mayor desregulación del mercado laboral y financiero y la promoción de la competencia. 
Los objetivos del programa de ajuste fueron los ya conocidos: el control de la inflación, el estímulo a la inversión privada, un mejor acceso a los recursos financieros, unos precios competitivos internacionalmente y un crecimiento estable y duradero. Y todo ello en un amplio, más eficiente, competitivo y creciente espacio económico capaz de competir mundialmente.

\section{b) Nuevos bríos para la integración andina en los años 90}

A finales de los años 80 se recuperó el interés por la integración latinoamericana debido en parte a que en las políticas económicas de la región latinoamericana predominaban las corrientes partidarias de la liberalización externa. El Grupo Andino, que había acordado sus nuevas bases en el Protocolo de Quito, vivió un momento de reactivación. A partir de este momento los presidentes de los países miembros empezaron a reunirse semestralmente con el empeño de reavivar la integración subregional. En 1990 se acuerda formar una Zona de Libre Comercio (ZLC) ${ }^{13}$ que entró en pleno funcionamiento en 1994. En 1991 se aprobó la adopción de un AEC y del Sistema Andino de Franjas de Precios (SAFP) que entrarían en funcionamiento en 1995. LaZLC y el AEC entraron en vigencia en Bolivia, Ecuador, Colombia y Venezuela. Perú se automarginó en el proceso de negociación, proponiendo su incorporación gradual a la ZLC y quedando como país observador en lo referente al AEC. Perú, actualmente, está en un proceso de desgravación progresiva con Colombia, Ecuador y Venezuela, manteniendo aproximadamente un $50 \%$ de sus productos en la ZLC; además tiene un acuerdo de ZLC con Bolivia.

Los cambios provocados en los últimos años se han manifestado a través de la supresión de los programas industriales, de la armonización legislativa para poner en marcha la ZLC y el AEC; también, de la ampliación de las facultades discrecionales en el Régimen Común sobre el capital extranjero y del robustecimiento de los órganos políticos intergubernamentales del Acuerdo de Cartagena en detrimento de los órganos de carácter comunitario. En 1979, se creó el Consejo Andino de Ministros de Relaciones Exteriores y en 1990, el Consejo Presidencial Andino. Se trata de dos órganos de carácter político de más alta jerarquía que la Junta, que era la institución comunitaria

13 Es el área o espacio donde las mercancías de dos o más países circulan libremente, sin restricciones de ningún tipo y sin pagar aranceles, como si lo hicieran dentro de un mismo territorio, pero sin adoptar todavía un arancel externo común. 
creada por el Acuerdo de Cartagena y que en estos años vio recortadas sus competencias, llegando incluso a sufrir problemas presupuestarios.

El último gran impulso en la historia de la integración andina tuvo lugar el 10 de marzo de 1996 en la ciudad peruana de Trujillo, en la que se aprobó una nueva estructura institucional más acorde con las nuevas ideas sobre la integración. La nueva estructura institucional dio paso a la Comunidad Andina de Naciones (CAN) y el Sistema Andino de Integración (SAI).

\section{c) La integración andina hoy}

El 1 de agosto de 1997, el Pacto Andino se transformaba en la Comunidad Andina y el proceso andino de integración se veía reforzado en su dirección política más allá de lo puramente comercial y económico. Se estableció su Secretaría General en la Ciudad de Lima.

Por todo lo dicho, la Comunidad Andina está integrada actualmente por Bolivia, Colombia, Ecuador, Perú y Venezuela, y por los órganos e instituciones del Sistema Andino de Integración.

\section{Gráfico 1 \\ Instituciones del Sistema Andino de Integración}

\section{Consejo Presidencial Andino}

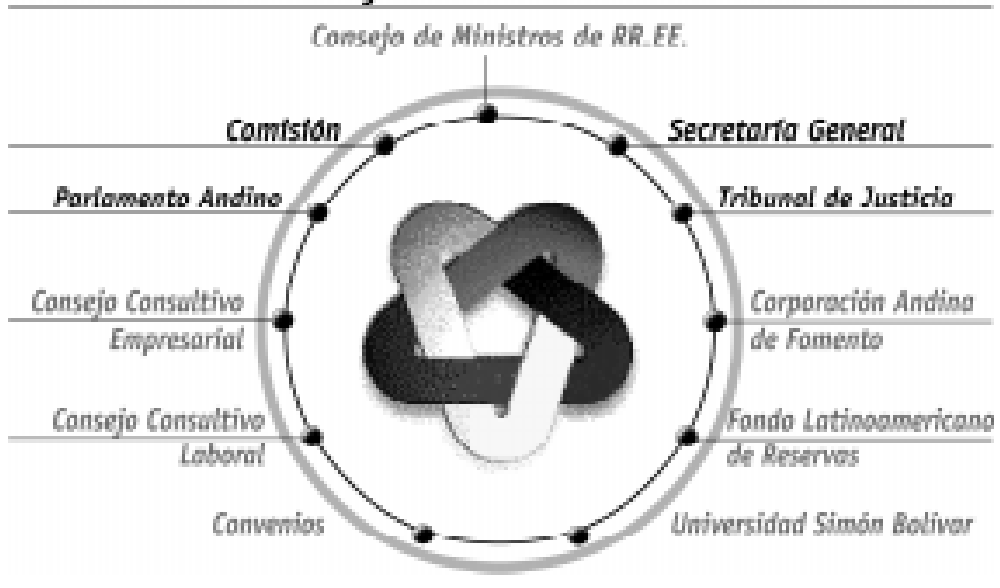

Fuente: Comunidad Andina. 
Los objetivos generales de la Comunidad Andina son: promover el desarrollo armónico y equilibrado de sus países miembros; acelerar su crecimiento por medio de la integración y la cooperación económica y social; facilitar la participación de los países andinos en la ALADI, con miras a la formación de un mercado común latinoamericano y el mejoramiento persistente en el nivel de vida de los habitantes de la subregión.

Como se puede apreciar, los planteamientos generales no han cambiado sustancialmente frente a los originarios de 1969. Sí ha cambiado el contexto económico y político internacional y la concepción de integración que los países andinos tienen hoy. Han pasado de una concepción cerrada de integración hacia adentro, en consonancia con el modelo de sustitución de importaciones, a una concepción abierta hacia el exterior, de regionalismo abierto.

Algunos de los mecanismos y acuerdos que la Comunidad Andina está utilizando para conseguir estos objetivos son:

\section{Consolidación de una Zona de Libre Comercio (ZLC)}

La creación de una Zona de libre Comercio para la subregión es considerada hoy un logro en la integración andina. La formación de esta zona de libre comercio ya estaba contemplada en los programas de liberalización del Acuerdo de Cartagena y culminó con la apertura de los mercados de Bolivia, Colombia, Ecuador y Venezuela. Perú, que se mostró reticente en un principio a ingresar en la ZLC, se está incorporando de forma gradual y conseguirá su incorporación plena en el 2005.

La ZLC andina presenta dos características singulares: todos los productos de su universo arancelario están liberalizados, no apareciendo ningún producto sujeto a excepción como en otros esquemas de integración y se ha constituido como un paso intermedio hacia la Unión Aduanera ${ }^{14}$ antes y el Mercado Común Andino después.

14 Recordamos que la Unión Aduanera es una forma de integración económica que consiste no sólo en suprimir las barreras aduaneras entre los países miembros, sino también en crear un arancel externo común con relación al resto del mundo. 


\section{Cuadro $n=7$}

Evolución del comercio intra-andino

\begin{tabular}{|l|r|r|r|}
\hline & 1996 & 1997 & 1998 \\
\hline Exportaciones intra-andinas (1) & $-1,5$ & 19,6 & $-5,2$ \\
\hline Exportaciones intra-andinas sin combustible (1) & $-4,5$ & 16,6 & 1,2 \\
\hline $\begin{array}{l}\text { Participación de las exportaciones intra-andinas } \\
\text { en las exportaciones andinas al mundo (\%) }\end{array}$ & 10,3 & 11,8 & 13,8 \\
\hline Exportaciones andinas al mundo (1) & 20,6 & 4,2 & $-18,9$ \\
\hline
\end{tabular}

Fuente: Comunidad Andina. (1) tasa de evolución anual

La liberalización total en el intercambio de los productos de la subregión se ha visto reflejada en un fuerte incremento del comercio intra-andino que pasó de 2.868 millones de dólares en 1993 a 5.626 en 1997. Éste ha sufrido en 1998 una caída del 5,2 \% que contrasta con el aumento de casi el $20 \%$ del año anterior y el crecimiento medio del $29 \%$ del período de 1990-1995. Es importante destacar que las exportaciones, excluyendo combustibles, crecieron $1,2 \%$ en 1998, por lo que parte del retroceso en las exportaciones de este año ha sido motivado por la caída de los precios del crudo.

El establecimiento de un Arancel Externo Común (AEC)

La Comunidad Andina inició, a partir del 1 de febrero de 1995, la etapa de Unión Aduanera al entrar en vigencia el Arancel Externo Común. EI AEC fue suscrito por todos los países miembros con la excepción de Perú y determina unos márgenes de preferencia homogéneos y razonables a favor de los países de la Comunidad que además sirven de base para fijar márgenes de preferencia en beneficio de otros grupos o países, dejando la puerta abierta a la convergencia con otros procesos de integración económica.

Este arancel se caracteriza por tener un promedio aritmético, poco disperso, del 13,6 \%. Se establece teniendo en cuenta el grado de elaboración de los productos, la existencia o no de producción subregional y el interés de no encarecer los bienes de capital y los insumos necesarios para los procesos productivos. Su estructura cuenta con 4 niveles arancelarios básicos: 5, 10, 15, 20 por ciento que se aplican conforme al grado de elaboración de los productos. 
Para los productos agropecuarios de primera de necesidad y caracterizados por una marcada inestabilidad de sus precios internacionales, se ha adoptado un el Sistema Andino de Franjas de Precios (SAFP) que es un mecanismo de estabilización de precios consistente en la fijación de un nivel piso y de un nivel techo, entre los cuales se desea mantener el coste de la importación mediante la modificación del arancel "ad valorem".

En el 2005 está previsto el pleno funcionamiento del AEC y la ZLC para pasar de la fase actual de Unión Aduanera y comenzar la fase de Mercado Común Andino.

\section{La formación del Mercado Común Andino}

Para encarar este nuevo reto que deberá completarse en el año 2005, la Comunidad Andina debe ir avanzando en campos como la liberalización del comercio de servicios, la armonización de políticas macroeconómicas, la apertura de compras del sector público o una Política Agraria Común. Y deberá poner en marcha las cuatro grandes libertades de circulación: de bienes, de servicios, de capitales y de personas. Además se está avanzando en el diseño de una Política Externa Común.

Profundización de la integración con los demás bloques económicos regionales y de relación con esquemas extrarregionales

En los últimos años, la Comunidad Andina ha avanzado de forma coordinada para desarrollar el comercio fuera de la subregión. Esto se ha reflejado en la participación activa de la Comunidad en las negociaciones del Área de Libre Comercio de las Américas (ALCA) para la liberalización del comercio en todo el hemisferio antes del año 2005. También se encuentra en negociaciones con Canadá, con el Mercado Común Centro Americano (MCCA), el Tratado de Libre Comercio de América del Norte (TCL o NAFTA en inglés) y Panamá. Con la Comunidad del Caribe (CARICOM) no se ha pasado de tener una reunión técnica de intercambio de información y con Mercosur se ha firmado un Acuerdo Marco para la creación de una zona de libre comercio entre ambos bloques. Además Perú se integró al Foro de Cooperación Económica de la Cuenca del Pacífico (APEC) a finales de 1998 y Ecuador ha solicitado su ingreso en este mismo Foro. 


\section{Cuadro $n=8$ \\ Exportaciones FOB de la Comunidad Andina por zonas económicas (millones de dólares)}

\begin{tabular}{|l|r|r|r|r|r|r|}
\hline & 1993 & 1994 & 1995 & 1996 & $1997 *$ & $1998 *$ \\
\hline Intra-andino & 2.868 & 3.428 & 4.718 & 4.705 & 5.628 & 5.333 \\
\hline Mercosur & 921 & 1.216 & 1.479 & 1.642 & 1.979 & 1.490 \\
\hline MCCA & 565 & 623 & 631 & 774 & 911 & 749 \\
\hline CARICOM & 679 & 1.217 & 609 & 579 & 391 & 373 \\
\hline TLC (Canadá, EEUU y México) & 14.410 & 15.379 & 16.205 & 22.433 & 22.800 & 17.464 \\
\hline Unión Europea (15 países) & 4.834 & 6.403 & 7.183 & 7.211 & 6.982 & 6.235 \\
\hline Asiáticos (1) & 1.813 & 2.192 & 2.690 & 2.467 & 2.704 & 2.163 \\
\hline Total exportado & 29.739 & 34.252 & 37.936 & 45.747 & 47.677 & 38.679 \\
\hline
\end{tabular}

Fuente: Comunidad Andina

(1) China, Japón, Taiwan, Hong Kong, Corea, Irán, Israel, entre otros. * cifras provisionales

Como ocurre en otros procesos de integración subregional en América Latina, por ejemplo en Centroamérica, el dato del comercio intrarregional es una cifra esencial para valorar la potencialidad de los acuerdos. El contraste que muestra el gráfico 6 entre el $16 \%$ de exportaciones intrarregionales y el $53 \%$ de las exportaciones a los países del TLC, ilustra las dificultades que encuentra el proceso de integración y explica la vulnerabilidad de los acuerdos andinos ante las propuestas hemisféricas de libre comercio que hace Estados Unidos. El incremento de los porcentajes de comercio intrarregional es una objetivo prioritario de los acuerdos de integración. 


\section{Gráfico 2 \\ Exportación FOB de la Comunidad Andina por zonas económicas en 1998}

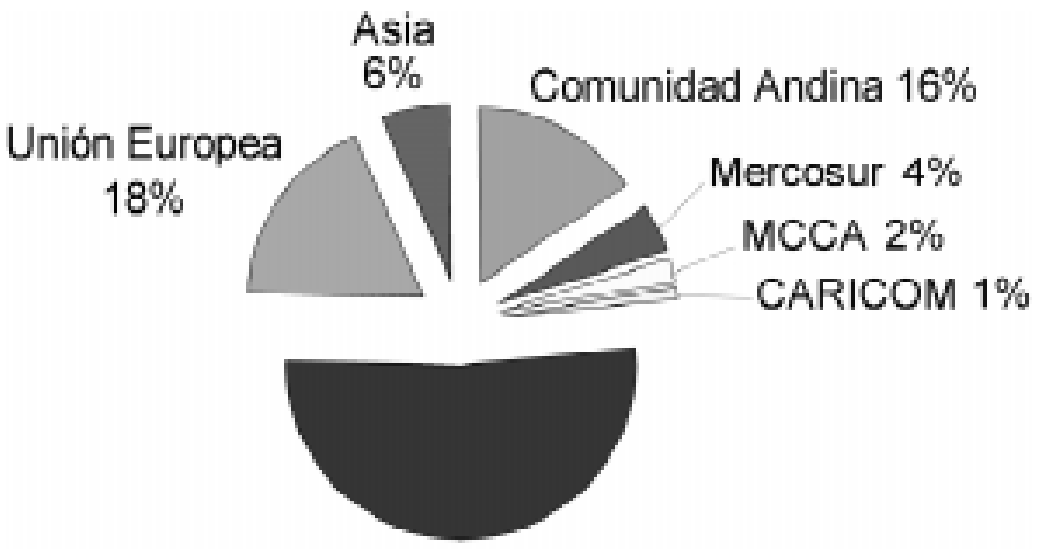

TLC (Canadá, EE.UU y México) 53\%

Fuente: elaboración propia a partir de datos de la Comunidad Andina.

En 1997 se estableció un Consejo Andino-estadounidense sobre comercio e inversión y se amplió la Ley dePreferencias Arancelarias Andinas (ATPA) ${ }^{15}$. EEUU es el primer socio comercial de los países de la Comunidad Andina que supone que el $45 \%$ de las exportaciones andinas al mundo se destinan al mercado de los Estados Unidos y el $35 \%$ de las importaciones andinas del mundo proceden de este país.

Desde 1990, los países miembros de la Comunidad Andina con la excepción de Venezuela, se benefician del acceso preferencial de sus productos a la Unión Europea (UE) en virtud de un Régimen Especial de Preferencias. La UE con el $18 \%$ de las exportaciones es el segundo mercado de destino de los productos andinos. Entre 1993 y 1997, las exportaciones de la Comunidad Andina a UE crecieron alrededor del $40 \%$ y en contrapartida los productos provenientes de UE hacia la Comunidad crecieron un $80 \%$.

Los intercambios entre la Comunidad Andina, los EEUU y la Unión Europea

15 Ley aprobada por el Congreso de los Estados Unidos el 4 de diciembre de 1991 para apoyar la lucha contra las drogas, beneficia con reducciones arancelarias a la mayoría de las importaciones provenientes de los Países de la Comunidad Andina.

\section{RFS}


están caracterizados por unas exportaciones andinas altamente diversificadas, procedentes del sector minero, petrolífero, agrícola y alimenticio. Y unas importaciones concentradas en pocos productos, sobre todo insumos y equipos industriales.

\section{Conclusiones}

La Comunidad Andina tuvo desde sus orígenes una vocación integracionista que sobrepasaba la creación de una zona de intercambio comercial entre países y ha tenido que esperar al final de la década de los 90 para que el sueño de la creación de una zona integrada política, económica y socialmente, parezca cercano. En estos momentos se desarrolla la Unión Aduanera, ya se ha puesto fecha para la creación del Mercado Común Andino y se están adoptando compromisos para que, además de ir hacia la integración económica, se avance hacia la integración política y social. Sin embargo, es importante tener en cuenta que todos estos planteamientos y avances surgen de la retórica política de los principales dirigentes andinos. Y aunque no se puede negar el incremento en los flujos comerciales entre los países miembros, la Unión Aduanera está teniendo serios problemas para consolidarse, y la mayoría de los países de la subregión están viviendo una aguda crisis económica y política. Todo esto no augura un porvenir fácil ni para la consolidación de las etapas de integración económica ni para la puesta en marcha de la integración política y social.

Si quiere consolidarse y ser una auténtica alternativa al desarrollo de la subregión, la Comunidad Andina tendrá que afrontar con determinación los retos internos y externos que los próximos años le presentan. Algunos de estos retos son:

- Consolidar las instituciones del Sistema Andino de Integración para que ganen en coherencia, cohesión y unidad.

- Convertir la Secretaría General de la Comunidad en una organización ágil y eficiente.

- Afianzar el mercado ampliado subregional para que se alcance sin problemas el Mercado Único en el año 2005.

- Avanzar en la integración física de la subregión y con los países del Cono Sur, a través de la creación de corredores interoceánicos.

- Facilitar la participación de la sociedad civil en el proceso de integración 
como interlocutora de los gobiernos para impulsar el proceso y lograr mayores éxitos en materia de integración.

- Desarrollar una agenda social que diseñe una política sociolaboral, educativa y cultural que contribuya al fortalecimiento de la identidad andina y al desarrollo integral de sus habitantes.

- Luchar contra la pobreza en el ámbito regional y convertir esta política en una de las prioridades de la integración.

- Hacer efectiva la Política Externa Común de la Comunidad Andina en el campo político, económico-comercial y sociocultural como expresión concreta de su propia identidad.

- Formar la ZLC con Mercosur para aprovechar una situación geoestratégica favorable que conectaría el Atlántico con el Pacífico y abriría un potencial inmediato de crecimiento.

La Comunidad Andina apuesta por la creación de una Zona de libre Comercio con el TLC más Panamá y está asumiendo cierto protagonismo en las negociaciones del ALCA. Esto abre un debate acerca del modelo teórico de integración de la CAN. Caldentey y Romero ${ }^{15}$ planteaban esta misma problemática para la experiencia centroamericana de la siguiente manera:

\begin{abstract}
"la opción integracionista no pretende concentrar las posibilidades del desarrollo en la propia región. No supone, por ejemplo, el abandono del estrechamiento de relaciones comerciales con Estados Unidos o el rechazo de opciones como la del, todavía lejano, Área de Libre Comercio de la Américas (ALCA), que son ineludibles a la vista de la cifra de comercio intrarregional (...).

Se trata, por tanto, de establecer acuerdos asimétricos y preferenciales, lo que no parece sencillo en las condiciones políticas actuales en EEUU. La integración podría tener efectos positivos al respecto por un doble motivo. En primer lugar, al reducir la dependencia del mercado estadounidense y diversificar las opciones comerciales de la región. En segundo lugar, porque potenciaría la formación de equipos negociadores más sólidos $\mathrm{y}$, sobre todo, porque un mercado centroamericano unido presenta argumentos más atractivos en una posible negociación comercial.
\end{abstract}

Esta posibilidad exige el abandono de estrategias unilaterales de negociación comercial si éstas presentan incompatibilidades con las negociaciones multilaterales o con los acuerdos centroamericanos. La indecisión de algunos gobiernos centroamericanos sobre la integración ha dado lugar a negociaciones unilaterales que han provocado incumplimiento de los acuerdos y, sobre todo, una cierta pérdida de legitimidad ente la opinión pública regional e internacional. El abandono de estrategias de negociación unilateral forma parte de la definición de las posturas que exige el proyecto regional".

16 Caldentey, P. y Romero, J J ., (1999), pp. 12-13. 
Al igual que Centroamérica, la Comunidad Andina tiene al TLC, y a los EEUU como principal destino de las exportaciones intrarregionales (ver cuadro 8) y defiende la compatibilidad y la complementariedad de ambos mecanismos: el acuerdo subregional de integración y la Constitución del ALCA y la ZLC con el TLC. Sin embargo parece difícil que se pueda consolidar el AEC andino y concluir una Unión Aduanera que consolide el mercado de la subregión y mantenga unos niveles de precios estables si simultáneamente se crea una Zona de Libre Comercio con EEUU.

Como hemos visto, los dirigentes andinos continúan expresando unánimemente la voluntad de seguir adelante con el proceso de integración andina. Aunque es importante no perder de vista que los países miembros siguen teniendo individualmente estructuras productivas muy dependientes que les hacen vulnerables ante cambios en la economía internacional; por ejemplo la bajada de los precios del petróleo en 1998 o la subida de estos en el año 2000. También siguen manteniendo unos altos niveles de endeudamiento externo y se ven condicionados a la hora de definir sus políticas nacionales por las directrices de política económica que se les imponen desde el exterior.

Sin embargo, casi todos los países de la región se encuentran inmersos en crisis políticas con una tremenda repercusión en su economía y en el proceso de integración. La crisis en Ecuador o Bolivia, la retirada de Fujimori y la convocatoria de elecciones en Perú, el conflicto de Colombia o la inestabilidad de Venezuela, tienden a hacer pasar a la integración a un irremediable segundo plano.

Tampoco conviene olvidar que la subregión andina sigue siendo pobre y con unos niveles irritantes de injusticia social, de falta de equidad en la distribución de la renta y desigualdad de oportunidades.

Los 30 años que cumplió la integración andina el año 1999 se celebraron dentro de la lógica alegría pero no conviene olvidar que es un camino que los países andinos han elegido recorrer y soñar en conjunto, y que el trecho para construir un futuro de bienestar y dignidad para todos será largo en trabajo y esfuerzo. Como le decía Gabriel García Márquez a la juventud latinoamericana: "No esperen nada del siglo XXI porque es el siglo XXI el que los espera a ustedes. Un siglo que no viene hecho de fábrica sino listo para ser forjado por ustedes a nuestra imagen y semejanza, y que sólo será glo rioso y nuestro como ustedes sean capaces de imaginarlo." 


\section{Bibliografía}

AKAL Ediciones (1998), El estado del mundo 1999, Madrid, Ed. Akal.

Alegrett, S. (1997), "Situación y perspectivas de la integración andina". VII Congreso Nacional de la Empresa Privada, Lima (Perú), 11-12 de noviembre de 1997.

Alegrett, S. (1998), "La Comunidad Andina y las relaciones hemisféricas", Business Future of the Americas, ponencia. Lima (Perú), 17 de noviembre de 1998.

Atienza Azcona, J. (1998), La deuda externa y los pueblos del Sur. El perfil acreedor de España, Madrid, Ed. Manos Unidas, Cáritas, CONFER, Justicia y Paz.

Caldentey del Pozo, P. (2000), El desarrollo económico de Centroamérica en el marco de la integración regional, Tesis doctoral, Córdoba, Ed. Banco Centroamericano de Integración Económica, Tegucigalpa.

Caldentey, P. y Romero, J J. (1999), Comunicación: “Centroamérica ante la globalización: integración regional y política agraria". 1a Reunión de Economía Mundial. Huelva, 27 y 28 de mayo de 1999.

CÁrdenAs, M.J . (1999), Ponencia: “Presente y futuro de la integración andina en el contexto latinoamericano y global con miras al siglo XXI". Reunión Extraordinaria del Comité de Representates de la ALADI para celebrar el XXX aniversario de la suscripción del Acuerdo de Cartagena. Montevideo (Uruguay), 19 de mayo de 1999.

CEPAL (1996), Anuario estadístico de América Latina y el Caribe, Chile, Ed. CEPAL.

Comunidad Andina (1999), www.comunidadandina.org.

IRELA (1992), Prospects for the processesof sub-regional integration in Central and South America, Madrid, Ed. IRELA.

MatTLI, W. (1999), The logic of Regional Integration, United Kingdom, Ed. Cambridge University Press.

PNUD (1996), Informe sobre desarrollo humano 1996, Madrid, Ed. MundiPrensa.

Roderos, C. (1999), Comunicación: "Regionalismo y globalización". II Foro Empresarial Andino, Santa Cruz de la Sierra (Bolivia), 19 de junio de 1999.

\section{RFS}


Romero, M. (1999), "La Comunidad Andina: entre la crisis y la falta de identidad", Ecuador Debate, no 47, agosto, pp. 65-90

SALGADO, G. (1995), “El grupo Andino: entre dos concepciones dela integración económica", Síntesis, no 24, julio-diciembre, pp.69-116.

Secretaría General de la Comunidad Andina (2000), Resumen Ejecutivo de los Indicadores Mensuales de la Comunidad Andina, Doc. SG/di 90-23, Lima, Ed. Comunidad Andina.

-(2000), Indicadores de la Comunidad Andina, Mercosur y Chile, Doc. SG/di 243, Lima, Ed. Comunidad Andina.

-(1999), Evaluación de las exportaciones intra-Comunidad Andina 19961998, Documento, Lima, Ed. Comunidad Andina.

Toranzo, C. (1998), "Banzer: un año de gobierno", Revista cuarto intermedio, no 48, agosto, pp. 34-61.

Vilaseca I Requena, J . (1994), Los esfuerzos de Sísifo, La integración económica en América Latina y el Caribe, Madrid, Ed. Los libros de la catarata. 